\title{
UNA LLAMADA AL LECTOR: LOS HUECOS EN LA ESCRITURA DE CHANTAL MAILLARD
}

\author{
Anna Tort Pérez*
}

\begin{abstract}
RESUMEN: En este artículo, se analiza la escritura de Chantal Maillard en relación con la importancia de los huecos en la estructura textual de la obra. Partiendo de la posición del lector, se revisan los rasgos de hipertextualidad presentes en la escritura maillardiana. Desde la convicción de que el espacio es un elemento que genera sentido, tanto en cada uno de los libros como en la red trazada entre todos ellos, se interpreta el quehacer textual de la autora como una llamada al lector. Este, como exigencia de la propia disposición de la obra, se ve impelido a configurar una nueva realidad a partir, no tanto de lo dicho, sino de lo sugerido; no tanto de lo presente, sino de lo ausente.
\end{abstract}

PALABRAS CLAVE: Chantal Maillard. Hueco. Lector. Hipertexto.

\section{Introducción: la erótica del texto}

Jean Paul Sartre escribió en Qu'est-ce que la littérature que "Écrire, c'est faire appel au lecteur pour qu'il fasse passer à l'existence objective le dévoilement que j'ai entrepris par le moyen du langage" (SARTRE, 1948, p. 59). En esta llamada radica, según el filósofo francés, la libertad que toda escritura exige al lector para que este haga emerger un sentido desde un espacio intersticial, a medio camino entre el escritor y el lector. Este espacio intermedio es el de la obra. Y la obra, que no tiene ninguna existencia si no es a partir de la actualización individual de quien la lee, es virtual en el sentido de que solo mediante la operación lectora se podrá concretar. Leer es, desde esta perspectiva, situarse en una mesa de operaciones donde el resultado no será ni el que opera ni el operado, sino una nueva realidad inestable que surgirá de la acción.

\footnotetext{
* Grupo de Investigación Hermeneia Estudios Literarios y Tecnologías Digitales, Universitat de Barcelona. E-mail: tortperez@gmail.com
}

\section{(oc) EY-NC-ND}

Esta obra está licenciada com uma licença Creative Commons. 
Decir que la obra es virtual, como propone Pierre Lévy a propósito del hipertexto ${ }^{1}$, supone entenderla como una situación potencial y, por consiguiente, colocar al lector en una posición preeminente. Stanley Fish habla en este sentido del texto como suceso y Edward Said lo relaciona con un acontecimiento. El significado, en cualquiera de las dos definiciones, tiene que ver con el acto comunicativo y no solo con una porción significativa surgida del texto. Es en este acto comunicativo donde, en la encrucijada escritor-texto-lector, emerge lo que tradicionalmente hemos atribuido a la interpretación de las obras. Contra esta interpretación escribió Susan Sontag el ensayo Against interpretation, donde se quejaba de la agresión que ejercemos sobre los textos cuando nos obsesionamos por descodificarlos, por el qué significan. Por ello, Sontag, reivindicando un vuelco hacia el cómo son los textos, habla de seducción frente a interpretación: "In place of hermeneutics we need an erotics of art" (SONTAG, 1966, p. 14).

El erotismo implica un juego velado entre lo que está (el texto) y lo que, por medio de la insinuación, somos capaces de producir mediante nuestra imaginación. Así, podemos, como en las buenas metáforas, crear mentalmente algo que se nos presenta oculto, algo que literalmente no existe. Wolfgang Iser lo expresaba de esta forma: "El quale de los textos literarios se basa en que los textos pueden producir algo que todavía no son" (ISER, 1987, p. 131). Siendo esto así, parece evidente que, para poder llevar a cabo el ejercicio imaginativo, es necesario que aquello que representamos esté ausente. Esto es, para que podamos imaginar una nueva realidad es imprescindible que haya un espacio a partir del cual crearla. Esto se produce en el campo literario, según Iser, gracias a los lugares de indeterminación que nos ofrecen los textos. De esta forma, los huecos, lejos de ser una ambigüedad gratuita, son el mejor garante para el compromiso del lector. En este sentido, cuanto más "ahuecado" sea un texto, mayor será la participación

\footnotetext{
1 Pierre Lévy en ¿Qué es lo virtual? define el hipertexto como una "matriz de textos potenciales" (1999, p. 39). Haciendo una oposición entre lo virtual y lo actual, explica que las combinaciones o interpretaciones que elaboramos son actualizaciones y no realizaciones porque no suponen una posibilidad previa y estática que deba materializarse sino que se constituyen como respuesta a un conjunto problemático planteado. Esta respuesta, no contenida en el enunciado, emana inevitablemente de un proceso creativo que hace del lector un agente fundamental en la configuración del sentido: "La actualización es creación, invención de una forma a partir de una configuración dinámica de fuerzas y finalidades" (1999, p. 18).
}

Texto Digital, Florianópolis, Santa Catarina, Brasil, v. 11, n. 2, p. 18-34, jul./dez. 2015. ISSNe: 1807-9288. 
requerida. A eso se refería Sartre, según mi opinión, cuando hablaba del engagement del acto literario: solo de esa libertad del lector, obligado a crear a partir de lo que el autor revela con y en el lenguaje, surge el compromiso compartido de forjar una nueva realidad.

La obra de Chantal Maillard, pensadora y escritora de origen belga en lengua castellana, se configura como una red textual en la que el hueco adquiere una relevancia fundamental. La continuidad que la autora traza entre todos sus textos es, paradójicamente, una continuidad discontinua, porque es el lector el encargado de producir los enlaces, dándoles una dimensión ausente en los libros concebidos como objetos aislados. Este ejercicio arácnido se da siempre en el acto literario, pero adquiere una dimensión notable en la escritura maillardiana. $Y$ es que la autora dispone intencionadamente una malla para ofrecerle al lector un eslabón más en la reflexión acerca de su propia naturaleza. Una naturaleza, fragmentaria y discontinua, que es paralela a la propia naturaleza del texto, representada en la escritura de Maillard como un objeto más para la observación. Este quehacer textual, centrado en los huecos y su repercusión en la actividad lectora, es el que se estudia en las páginas que siguen.

\section{Los huecos en la obra de Chantal Maillard: una Ilamada al lector}

La escritura de Chantal Maillard apunta al blanco². Esto es así no solo porque en muchos de sus textos la autora haga referencia a lo que la palabra no puede decir, sino porque, en el territorio de la página, el espacio se convierte en un elemento significante. Es significativo el espacio en muchos de sus libros, estructurados de forma fragmentaria (subtítulos, notas al margen, intervalos, etc.), y es significativo el espacio entre diferentes obras que se interpelan entre ellas y que obligan al lector a reformular las conexiones. Su obra se asemeja en este sentido a un mapa que hay que recorrer a medida que se va dibujando. Podríamos pensar también en un álbum, como apuntó Wittgenstein en el prólogo de sus Investigaciones filosóficas:

\footnotetext{
2 Así lo leemos en unos versos del poema extenso Escribir, que sigue a Matar a Platón: "escribir / para apuntar al blanco" (MAILLARD, 2004, p. 74).
}

Texto Digital, Florianópolis, Santa Catarina, Brasil, v. 11, n. 2, p. 18-34, jul./dez. 2015. ISSNe: 1807-9288. 


\begin{abstract}
Los mismos puntos, o casi los mismos, fueron continuamente tocados de nuevo desde diferentes direcciones y siempre se esbozaron nuevos cuadros. Un sinnúmero de éstos estaban mal dibujados o carecían de personalidad, aquejados de todos los defectos de un torpe dibujante. $Y$ cuando fueron descartados, quedó una cantidad de otros regulares que debían entonces ser ordenados, y frecuentemente recortados, para que pudieran darle al observador un cuadro del paisaje. -Así pues, este libro es en realidad sólo un álbum. (WITTGENSTEIN, 2004, p. 12-13).
\end{abstract}

Esta idea del esbozo o del álbum se ajusta también a la obra de Chantal Maillard. La autora, lejos de la tripleta aristotélica inicio-nudo-desenlace, nos presenta una escritura que no explica nada, sino que, situándonos siempre in media res, muestra esbozos del proceso mental que la va configurando. Del mismo modo que Wittgenstein construye su proyecto a base de repeticiones, autorrefutaciones y contraejemplos que contradicen su propia teoría, encontramos en Maillard abundantes autorreformulaciones y reiteraciones que hacen que cada fragmento remita a todos al mismo tiempo y que imposibilitan una historia lineal y unitaria. Esta hipertextualidad detectada en la obra de Chantal Maillard no tiene que ver con una retórica electrónica, sino que tiene un alcance global, estructural, que responde a un pensamiento subyacente que se materializa irremediablemente en esta forma de proceder. Estos son algunos de los libros de Maillard en los que la no linealidad y la fragmentariedad, dos características atribuibles a la idiosincrasia del hipertexto, tienen un papel relevante: Filosofía en los días críticos (2001), Matar a Platón (2004), Husos. Notas al margen (2006), Hilos (2007) y Bélgica (2011).

En la primera de las obras mencionadas, Filosofía en los días críticos, como ocurre también en otros cuadernos (Diarios indios, Husos. Notas al margen, Adiós a la India), Maillard utiliza la unidad del fragmento, en forma de párrafos, identificados con un número en esta ocasión. Siguiendo esta numeración, la autora propone en el epílogo unos itinerarios de lectura, o "mapas de senderismo", que responden a distintos ejes temáticos. En esta lógica del fragmento, los recorridos, no solo los que propone la autora, son de una potencialidad combinatoria infinita. $Y$ es que el fragmento es una estructura lo 
suficientemente flexible para poder ser combinada siguiendo múltiples direcciones. De este modo, no hay en los párrafos del cuaderno una relación jerárquica de causa-efecto con el párrafo contiguo, sino que la contigüidad está presente únicamente en la página y está siempre interrumpida por un espacio entre fragmento y fragmento. Efectivamente, aunque podamos suponer que hay una continuidad cronológica que responde a la estructura diarística (los párrafos no están fechados), la sucesión se quiebra en la configuración del texto y en el itinerario que decida trazar el lector.

El fragmento es un bloque de texto que, como la lexía en el hiperetxto, goza de una gran movilidad. Esta unidad estructura la obra de Maillard en varios sentidos. Por una parte, porque el lector puede recomponer las piezas aisladas de diferentes libros que han sido reversionadas por la autora y construir de este modo un nuevo sentido inexistente en cada uno de los libros por separado. Por otra parte, porque, en el interior de muchos de los libros, lo que se dice aparece fragmentado en distintos espacios de escritura y de lectura (subtítulos, poemas, márgenes, intervalos, etc.). Estas piezas aisladas toman varias formas en función de la obra: versos en los poemarios, enunciados en prosa en los subtítulos o párrafos en lo que podríamos llamar prosa poética en Filosofía en los días críticos, Husos o Bélgica. Además, en los libros de poesía, la brevedad del verso propicia la estructura fragmentada y más si tenemos en cuenta que, en muchos casos, el verso se ha trasladado y reformulado a partir de fragmentos de otros libros. Se muestra, de esta forma, lo que la propia autora dice en el prólogo de Hainuwele y otros poemas: "un poema es apenas el fragmento de una hebra" (MAILLARD, 2009, p. 14).

Esta estructura que venimos comentando le permite a la autora señalar el hueco que según ella siempre se produce cuando pensamos o sentimos. Así, se plasma en el texto el propio proceso de pensamiento-escritura, que se da siempre interrumpidamente, a sacudidas, y no linealmente. En consonancia con esto, la línea, ya sea argumental, ya sea temporal, queda sustituida por una disposición que permite la multidireccionalidad y la maleabilidad de los temas tratados. El mismo tema se aborda en momentos distintos y en circunstancias distintas, como 
explica Maillard en una entrevista: "Porque el autor, además de escribir, también come, elabora discursos, mira por la ventana, atiende a su gato, siente frío, se enfada, discute, percibe colores, etcétera. Sin esa continuidad heterogénea, que es la trama de su existencia, la obra no se escribiría" (en CORTÉS, 2006).

Esta continuidad heterogénea es la que la autora trata de mostrar también en un nivel macrotextual, recontextualizando sus propios textos y dándoles de esta forma un nuevo sentido. Del diario Filosofía en los días críticos surgieron las dos segundas partes de los poemarios Conjuros (2001) y Lógica borrosa (2002). Aunque las reformulaciones en estos trasvases no sean tan significativas como en otros $\operatorname{casos}^{3}$, lo cierto es que, al cambiar la situación comunicativa y el género literario, los textos adquieren, sin duda, una dimensión distinta. Por otra parte, de algunos fragmentos de Husos nace la sección de "Poemas-husos" de Hilos. El cuaderno Bélgica, por su parte, desarrolla como tema principal (el trabajo de la memoria y el gozo) unos apuntes que aparecían en las dos últimas notas al margen de Husos. Estos son únicamente algunos ejemplos de la disposición hipertextual de la obra maillardiana. Aparte de los trasvases que Maillard realiza entre cuadernos y poemarios (Filosofía en los días críticos-Conjuros / Lógica borrosa; Husos-Hilos), encontramos continuamente una interpelación textual entre distintos textos. Pongo a continuación algunos ejemplos de este diálogo, ya sea entre poemas del mismo libro o entre poemas o fragmentos de obras distintas (la negrita es mía):

27

Se hizo de noche al mediodía.

No pude respirar.

Tanto metal entre la carne, aquel sabor a cieno

y sobre todo

El corazón oblicuo, sí, eso es, el corazón oblicuo.

Como las tejas de un tejado, resbalando.

tras la puerta embestida?

No lo haré.

\section{No me pregunten por el viento:}

El viento arriba

(había viento, sí, un viento suave).

[...]

(Matar a Platón, MAILLARD, 2004, p. 65)

\footnotetext{
3 Para ver un análisis exhaustivo de las reformulaciones textuales de Maillard, sobre todo en lo que atañe al tándem Husos-Hilos, recomiendo especialmente los estudios de Lola Nieto. En "Araña, otra lógica. La escritura como urdimbre en Chantal Maillard" (NIETO, 2013, p. 375-398), Nieto analiza la dinámica arácnida de la escritura maillardiana mediante una interesante comparación con la Reticulárea de Gego.
} 
yo no sé si lo había.

Y aunque así fuese, en todo caso,

sería irrelevante.

(Matar a Platón, MAILLARD, 2004, p. 15)
[...] El verdadero fin del deseo es el sentimiento mismo, el vuelco de la voluntad. Amo el amor, mi amor, cuando te amo. Amo amarte, deseo seguir amándote. $\mathrm{Y}$ por eso es tan penoso el desamor. No tanto por el objeto, puesto que éste ya no se quiere, sino por aquel desalojo: la ausencia del amor [...] (Filosofía en los días críticos, MAILLARD, 2001, p.188-189)

UNO

\section{$[\ldots]$}

Partir es dar pasos fuera.

Fuera de la habitación.

De la mente, no:

no hay. Hay hilo.

Partir es dar pasos

fuera de la habitación con el hilo.

El mismo hilo

(Hilos, MAILLARD, 2007, p. 13-14)
Amo el amor, dije alguna vez. Me refería a una sensación o a un estímulo. Sensación. Estímulo. Palabras que tampoco significan gran cosa. Debería haber dicho, haber sabido decir aquella tensión en mis venas, aquel latir que me llevaba hacia las leves señales de otro latir en el que deseaba perderme (Bélgica, MAILLARD, 2011, p. 77).

\section{HILOS}

\section{[...]}

Partir es dar pasos fuera.

Fuera de la habitación

De la mente, no. -¿Mente? -

Ya pregunté. Y no hay. Hay hilo.

Partir es dar pasos

fuera de la habitación

con el hilo. El mismo hilo.

La palabra silencio dentro.

Dentro de uno - ¿uno?

(Hilos, MAILLARD, 2007, p. 16-17)

Quedar en lo reconocible. Quedar - ¿quedar? -: permanecer. Ya dije

\section{LA CALMA}

permanecer. Ya pregunté. Quedar es permanecer por menos tiempo. Siempre se puede partir. Partir es dar pasos fuera. Fuera de la habitación. De la mente, no. - ¿Mente?- Ya pregunté. Y no hay. Hay hilo. Partir es dar pasos fuera de la habitación con el hilo. El mismo hilo. (Husos, MAILLARD, 2006, p. 64)

[..]

Avanzar es dar pasos fuera. Aunque eso ya lo dije en alguna parte, ¿o era partir?, partir es dar pasos fuera. Es igual. (Hilos, MAILLARD, 2007, p. 74)

Como vemos en estos ejemplos, la linealidad del texto se quiebra gracias a los 
huecos que advienen cuando el texto se divide y se disemina, ya sea en la página, en fragmentos del mismo libro o en libros diferentes, algunos muy distantes en el tiempo. Es evidente, sin embargo, que el proceso de lectura es siempre lineal, porque es una acción que sucede en el tiempo y, por tanto, es inevitablemente algo secuencial. Por ello, algunos teóricos del hipertexto sostienen que la idea de la no linealidad se asocia más a la estructura textual que al ejercicio de la lectura. Así pues, cuando hablamos de no linealidad lo hacemos, en todo caso, en relación con la distribución espacial del texto, que obliga a una determinada disposición del lector. "La característica principal del hipertexto afirma Aarseth- es la discontinuidad, el salto, el traslado repentino de la posición del usuario en el texto" (AARSETH, 1997, p. 90).

La multisecuencialidad, término usado por George P. Landow, tiene que ver con la idea del espacio más que con ejercicio de la lectura. De esta forma lo expresan Deleuze y Guattari: "Escribir no tiene nada que ver con significar, sino con deslindar, cartografiar, incluso futuros parajes" (DELEUZE Y GUATTARI, 2003, p. 12). No es extraña esta analogía, ya que el espacio (mapas, caminos, laberintos, tableros, estancias, etc.) es una metáfora muy empleada a la hora de hablar de hipertextualidad. También lo hace Maillard cuando desarrolla su topografía mental (husos-hilos; arriba-abajo; superficie-adentro, estancias, habitaciones...), que podemos equiparar con su topografía textual (arriba-abajo, poema-subtítulo, capítulo-intervalo, etc.). "Visualizar un mapa -dice Maillard en la entrevista antes citada- ayuda a andar por los recovecos mentales" (en CORTÉS, 2006). Y sus textos, que hablan de geografías mentales, tienden formalmente al mapa, más que a la secuencia de palabras.

En libros como Matar a Platón o Husos, por ejemplo, la distribución del texto es claramente no lineal aunque cuando leemos (sea cual sea el orden que escojamos) convertimos la lectura en trayecto, en tiempo, en línea. El espacio permite, no obstante, la ilusión de simultaneidad, lógica muy explotada en el arte y la literatura a partir del siglo XX, sobre todo en las vanguardias. La alteración del orden lineal, o hipérbaton textual, por utilizar metáfora de Jay David Bolter (2006) para hablar del hipertexto, nos sitúa, desplazándonos sistemáticamente por el 
espacio, en una lógica del ahora. Lo que acontece se esparce, así, en distintos escenarios y en una suerte de condensación temporal. En Matar a Platón, poemario con el que Maillard obtuvo el Premio Nacional de Poesía en 2004 y que toma la extraña forma de una VOS (Versión Original Subtitulada), la trama se estructura a partir de variaciones de una misma escena: transeúntes que contemplan un hombre que acaba de ser atropellado por un camión. Los subtítulos que encontramos en la parte inferior de cada página no glosan el contenido de los poemas sino que recrean una historia -una variación- que acontece en un mismo instante, como descubrimos al final del libro. Esta disposición permite, entonces, crearle al lector una ilusión de simultaneidad, al mismo tiempo que se da lugar, en el mismo espacio de la página, a distintos tiempos de escritura y de lectura.

Este mismo mecanismo lo encontramos en un cuaderno como Husos. Notas al margen, donde las notas no necesariamente amplían el fragmento al cual remiten sino que se despliegan de nuevo como otro lugar y tiempo de escritura. Además, cabe decir que, en algunas ocasiones, las notas no remiten a ningún fragmento sino a un numerito situado en un espacio en blanco. El referente, contraviniendo la idea de la mímesis, se pierde y no hay ni traducción ni explicación posible. De esta forma, el hueco se convierte, cuestionada la capacidad significativa del lenguaje, en un elemento protagonista. Asimismo, en este diario, distribuido en fragmentos y notas al margen, Maillard da una vuelta de tuerca más en su sistema de resonancias. La autora, esparciendo texto por las páginas, multiplica las versiones de lo que cuenta, o más bien de lo que muestra, porque el lenguaje, más que narrar, se somete a un ejercicio de sospecha y de "cirugía lingüística". De esta manera, la voz se va de-deformando -cambiando de forma- diciéndose "de otra manera" en cada uno de estos distintos espacios textuales. Unos espacios que, en el caso de Maillard, acaban remitiéndose los unos a los otros, en una suerte de efecto boomerang. Este movimiento es imprescindible porque es justamente la movilidad de la escritura lo que da sentido a este sistema, puesto que si nos instalamos en alguno de los espacios, aunque sea en los márgenes, corremos el riesgo de solidificarlo de nuevo, de convertirlo en argumento principal, en verdad. En este aspecto, la escritura maillardiana acaba topando siempre con 
los muros del lenguaje, como ilustran estas palabras Husos: "Y así, asolada, sin im-portancia, voy menguándome. Hasta que, con temor, me encuentro, de nuevo, como una nota a pie de página" (MAILLARD, 2006, p. 31).

Las notas al margen de Husos, en las que en varias ocasiones podemos leer aquellas condiciones de la escritura que escapan al argumento, se transforman en intervalos en Bélgica. También Fernando Pessoa tiene sus "Intervalos dolorosos" y "Pausas dolorosas" en la "Autobiografía sin acontecimientos" del Libro del desasosiego. Se trata de unas interrupciones sistemáticamente intercaladas a lo largo del libro, cuya estructura discontinua me recuerda mucho a la de Maillard. EI material errante toma, en Bélgica, forma de intervalos. Estos intervalos coinciden con los momentos entre viaje y viaje, de manera que el tiempo se acaba convirtiendo en espacio en la página. En un nuevo intento por encontrar un hueco en el magma textual, la autora halla un territorio por explotar lo que no se puede decir (la sensación de gozo, en el caso de Bélgica). El riesgo, sin embargo, sigue siendo el de acabar rellenando estos huecos con el mismo material narrativo que encontramos en la escritura "principal":

\footnotetext{
Los márgenes -o los intervalos-, de ser el lugar de lo superfluo o del añadido, de lo prescindible, se transforman de este modo en un lugar de narración posible. No deja de ser paradójico, por otra parte, que cualquier empeño por sacar a flote (aleatoriamente) ciertos episodios sumergidos se verá frustrado, pues se convertirán ipso facto en texto y, necesariamente, en señal de lo que queda por decir (Bélgica, MAILLARD, 2011, p. 32).
}

Hay en la obra de Maillard, gracias justamente a la importancia del hueco que se ha comentado aquí, una tensión dialéctica que hace que el lector tenga in mente varios textos de la autora simultáneamente. Esto se debe principalmente a la estructuración de una obra que se desarrolla como una suerte de escritura inacabada, "por entregas". La duda acerca de la próxima entrega, a diferencia de 
los textos novelescos donde lo que cuenta es el argumento, se vuelca, desde mi punto de vista, en la estrategia lingüística que empleará la autora. ¿Cómo escribir después de haber dilapidado el lenguaje? ¿Desde dónde escribir? ¿Qué forma tomarán los próximos márgenes?

Los textos maillardianos se nos sirven para que los redescubramos y para que produzcamos los enlaces invisibles que han llevado la autora a tejer una continuidad entre unos y otros. Este modus operandi obliga al lector a renunciar a las ideas preconcebidas sobre cada libro y a entregarse por completo a lo inmediato de la experiencia textual. Cuando uno está leyendo un poemario como Hilos, por ejemplo, tiene la sensación de lo que está leyendo ya lo ha leído en otra parte. No sabe si lo ha leído en el mismo poemario, en el cuaderno Husos, o si simplemente se lo está imaginando. Esta desorientación responde, sin duda, a un juego planificado y provocador por parte de la autora. Maillard, consciente de que miente y mienta ${ }^{4}$ en su escritura, le ofrece al lector este juego de pseudorrepeticiones para que este, desde la propia experiencia, experimente la naturaleza lingüística de todo pensamiento. De esta forma, el "ya dije", el "miento" o el "cito" de Maillard se instala en nuestra mente, no tanto a través de una reflexión sobre la cuestión, sino a través de una puesta en escena que nos obliga a descubrir la propia naturaleza del lenguaje, a partir de sus huecos.

La idea de la puesta en escena tiene mucha relación con la práctica textual maillardiana, que nos muestra el texto en su propia elaboración, en su constante autorreferirse. A propósito de la espacialización del texto, Walter Benjamin pretendía con su Arcades Project mostrar una historia en la que cada trozo fuera interdependiente de otros, creando un mosaico de escritos en una clara simbiosis texto-espacio. Maillard crea una escritura en la que el tiempo se sustituye por el espacio del texto. Un texto que, como leemos en la definición de intertextualidad de Julia Kristeva en "Bakhtine, le mot, le dialogue et le roman", no existe como algo acabado, sino que se va construyendo por absorción y transformación, a

\footnotetext{
${ }^{4}$ En el poema "El punto" (Hilos, MAILLARD, 2007, p. 27), como bien señala Virginia Trueba, encontramos un único verbo conjugado: "miento". Esta forma del verbo coincide significativamente tanto con el verbo mentir como con el verbo mentar (TRUEBA, 2009, p. 194).
}

Texto Digital, Florianópolis, Santa Catarina, Brasil, v. 11, n. 2, p. 18-34, jul./dez. 2015. ISSNe: 1807-9288. 
partir de lo que en rigor no existe:

Tout texte se construit comme mosaïque de citations, tout texte est absorption et transformation d'un autre texte. À la place de la notion d'intersubjectivité s'installe celle d'intertextualité, et le langage poétique se lit, au moins, comme double (KRISTEVA, 1969, p.146).

De nuevo nos encontramos con una metáfora espacial, la del mosaico, para referirnos a la naturaleza del texto. Recordemos que Deleuze y Guattari utilizaban la oposición entre el espacio liso y el espacio estriado en Mil Mesetas. El espacio liso, frente al espacio estriado, es propio del nómada, porque representa el devenir sin individualidad, sin causalidad, sin límite. Desde esta perspectiva, no importa tanto la localización momentánea como el recorrido. Y el recorrido surge a gracias al hueco a partir del cual podemos suceder, como lectores y como sujetos. Es lo que Maillard llama en alguna ocasión posibilidad:

\footnotetext{
Es tiempo de convertir las fronteras en flechas que apunten al ocaso, al reino de la Posibilidad, o al propio corazón, atravesando los límites de su encierro. Es tiempo de aprender a reír con una risa que disuelva los cercos y deje en libertad a eso que creemos "Ser" para que podamos cumplirnos en el suceso (La razón estética, MAILLARD, 1998, p. 130).
}

Este cumplirse en el suceso del que habla Maillard nos lleva a la asimilación pensamiento-lectura que, a mi parecer, observamos en la escritura estudiada. La autora utiliza la metáfora de los husos -estados de conciencia- y los hilos -temas que la mente agarra para conducirnos de un huso al otro- para explicar el modus operandi de nuestra conciencia. Cuando pensamos, según Maillard, nos vamos moviendo, según la modalidad anímica o de conciencia de cada momento, a través de los temas o hilos que, por inercia, la mente elige. De un modo simultáneo, la autora nos ofrece una obra en la que el método de lectura no difiere del propio mecanismo de la conciencia. Esto es, si pensar es atravesar husos, hilándonos de una modalidad a otra, leer es también atravesar textos, hilándonos como lectores de un fragmento a otro. En este proceso variable, ni el sujeto noción puesta permanentemente en duda- es unitario ni la lectura es única. Porque ni el sujeto es algo ininterrumpido, ni lo es el pensamiento, ni lo es la 
lectura. Por ello, considero que la escritura de Maillard goza de una gran coherencia ético-estética. Porque lo que la autora nos transmite nos llega por la vía de la experiencia, a través del tipo de lectura al que somos invitados y que nos conduce a una manera singular de conocer y de conocernos a través de las rendijas del lenguaje.

\section{Conclusión}

La mejor lectura, la que produce gozo, es la que se hace levantando la cabeza, en levant la tête. Lo decía Roland Barthes en Le plaisir du texte cuando afirmaba que las mejores revelaciones advienen cuando se está con alguien amado y se está pensando en otra cosa (BARTHES, 2007, p.18). Esta distracción de la mente tiene mucho que ver con la seducción de la que hablaba en la introducción de este artículo. En este sentido, lo importante no es tanto lo que se dice, sino lo que imaginamos a partir de lo ausente en lo dicho. Por ello, Barthes criticaba también la lectura del que consume historias simplemente con el fin de conocer el final de un argumento o de una trama. En cambio, en el polo opuesto, tendríamos al relector, al que produce sentido(s) gracias a la lectura cada vez diferente que proyecta sobre los textos. Este sería el reverso de una lectura lineal y siempre idéntica, porque "ceux qui négligent de relire s'obligent à lire partout la même histoire" (BARTHES, 1970, p. 22-23).

La obra de Chantal Maillard, siguiendo con Barthes, es, sin duda, un texto scriptible. En primer lugar, porque se teje como una galaxia de significantes y no como una estructura de significados (1970, p.12). En esta galaxia, los huecos adquieren, como se ha visto, un papel relevante. Gracias a estos recovecos, los caminos posibles, como ocurre en los laberintos multicursales, son muchos. En segundo lugar, porque es una obra que hace de la relectura un proceso insoslayable, ya que el lector se ve obligado a levantar constantemente la cabeza para imaginar los enlaces ocultos entre los textos (fragmentos y notas, poemas y subtítulos, etc.) y entre los libros.

"La obra es el hecho-constituido del texto en la conciencia del lector", afirma Iser Texto Digital, Florianópolis, Santa Catarina, Brasil, v. 11, n. 2, p. 18-34, jul./dez. 2015. ISSNe: 1807-9288. 
(ISER, 1987, p.122). La obra es, desde este punto de vista, un acontecimiento que solo tiene lugar cuando alguien lo representa, como percibimos claramente si pensamos en una pieza musical. $\mathrm{Y}$, si cada representación es absolutamente diferente, como distintas partidas de un mismo juego, también lo es la relectura que nos propone Maillard con sus textos. En efecto, a través de las fugas que nos brinda la autora, se nos invita a ramificarnos y a perdernos en las infinitas variaciones que resultan de la combinación infinita del lenguaje y sus huecos.

\section{UMA CHAMADA AO LEITOR: AS LACUNAS NA ESCRITA DE CHANTAL MAILLARD}

RESUMO: O artigo tem o objetivo de analisar as características da escritura de Chantal Maillard em relação à importância das lacunas na estrutura textual da obra. A partir da posição do leitor, o artigo discute as características do hipertexto presentes na escritura maillardiana. Considerando a convicção de que o espaço é um elemento que gera sentido, tanto em cada um dos livros como na rede traçada entre todos eles, o trabalho textual da autora é interpretado como uma chamada para o leitor. Este, como exigência da própria disposição da obra, se vê obrigado a configurar uma nova realidade a partir, não tanto do que foi dito, mas do que foi sugerido; não tanto do presente, mas do ausente

PALAVRAS-CHAVE: Chantal Maillard. Lacuna. Leitor. Hipertexto.

\section{A CALL TO THE READER: THE BLANKS IN THE WRITING OF CHANTAL MAILLARD}

ABSTRACT: In this article I analyse the writing of Chantal Maillard in accordance with the relevance of the blanks in the textual structure of the work. Starting from the reader's position, I revise the hypertextual features in Maillard's writing with the conviction that the blank is an element that makes sense, so much on each of her books, as on the net weaved among them. I consider the textual task of the authoress as an appeal to the reader. This one, as a demand of the own layout of the work, is urged to shape a new reality starting not so much from what is said, but from what is suggested; not so much from what is present, but from what is absent.

KEYWORDS: Chantal Maillard. Blank. Reader. Hypertext.

\section{Referencias}


AARSETH, Espen. "No linealidad y teoría literaria” en George P. LANDOW (comp.). Teoría del hipertexto, Paidós, Barcelona, 1997, pp. 71-108.

CORTÉS, Rafael. [Entrevista con Chantal Maillard]. "Lo que duele, duele menos si se proyecta fuera", Diario Sur Digital, Último acceso 21-06-2006. URL:

<11/11/2014,URL:http://www.diariosur.es/pg060621/prensa/noticias/Cultura/20060 6/21/SUR-CUL-236.html>.

DELEUZE, Gilles y GuATTARI, Félix. Rizoma, Valencia: Pre-Textos, 2003.

BARTHES, Roland. S/Z, Paris: Seuil, 1970.

. El placer del texto / Lección inaugural. Madrid: Siglo XXI de España Editores, 2007.

BOLTER, Jay David. "Ficción interactiva”, en María Teresa

VILARIÑO PICOS, Maria Teresa y AUBÍN GONZÁLEZ, Anxo. Teoría del hipertexto: La literatura en la era electrónica, Madrid: Arco Libros, 2006, pp. 243263.

FISH, Stanley. "La literatura en el lector: estética "afectiva»", en Rainer WARNING (ed.) Estética de la recepción, Madrid: Visor, 1989, pp. 111-131.

ISER, Wolfgang. "El acto de lectura. Consideraciones previas sobre una teoría sobre el efecto estético", en Dietrich RALL (comp.). En busca del texto. México: Universidad Autónoma de México, 1987, pp. 121-143.

KRISTEVA, Julia. "Bakhtine, le mot, le dialogue et le roman", en Critique, 239, 1969 , pp. 438-465.

LANDOW, George P (comp.). Teoría del hipertexto. Barcelona: Paidós, 1997. 
LÉVY, Pierre. ¿Qué es lo virtual? Barcelona: Paidós, 1999.

MAILLARD, Chantal. La razón estética. Barcelona: Laertes, 1998.

. Filosofía en los días críticos. Valencia: Pre-Textos, 2001.

. Conjuros. Madrid: Huerga y Fierro Editores, 2001.

. Lógica borrosa. Málaga: Miguel Gómez Ediciones, 2002.

. Matar a Platón. Barcelona: Tusquets, 2004.

. Husos. Notas al margen. Valencia: Pre-Textos, 2006.

. Hilos. Barcelona: Tusquets, 2007.

. Hainuwele y otros poemas. Barcelona: Tusquets, 2009.

. Bélgica. Valencia: Pre-Textos, 2011.

NIETO, Lola. "Araña, otra lógica. La escritura como urdimbre en Chantal Maillard", Contrastes: revista internacional de filosofía, 18, 2013, pp. 375-398.

SARTRE, Jean-Paul. Qu'est-ce que la littérature? Paris: Gallimard, 1948.

SONTAG, Susan. Against interpretation, New York: Dell, 1966.

TRUEBA, Virginia. "Volver a las palabras. (Sobre Hilos de Chantal Maillard)", Salina, 23, 2009, pp. 191-200.

WITTGENSTEIN, Ludwig. Investigaciones filosóficas. Barcelona: Crítica, 2004. 
Recebido em: 10/07/2015.

Aceito em: 27/07/2015.

Texto Digital, Florianópolis, Santa Catarina, Brasil, v. 11, n. 2, p. 18-34, jul./dez. 2015. ISSNe: 1807-9288. 